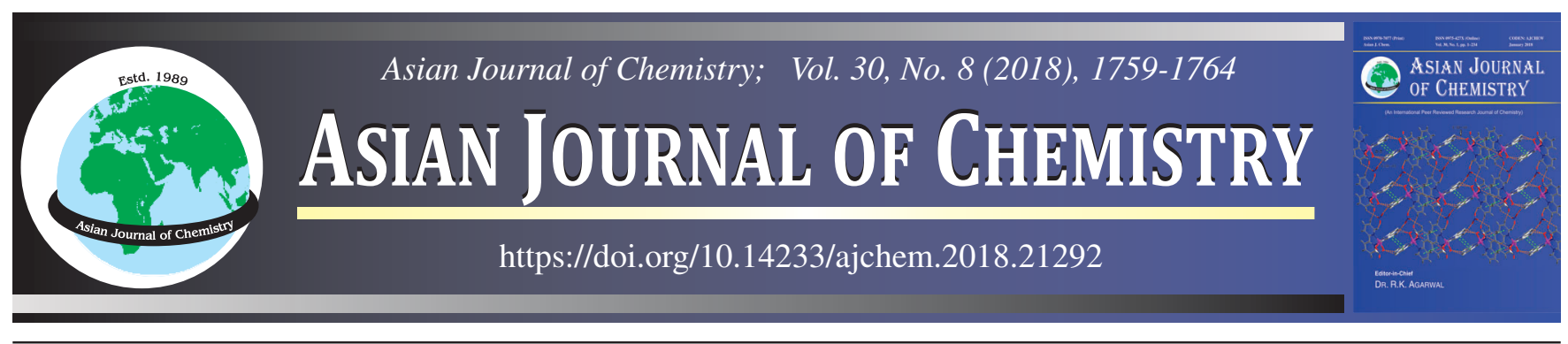

\title{
Thermodynamic Properties of Binary Mixtures of Methyl Benzoate with Chlorobenzene and Benzaldehyde at 308.15 and $318.15 K$
}

\author{
P. Prabhu* and A. Rose Venis
}

Department of Chemistry, St. Joseph's College, Tiruchirappalli-621 002, India

*Corresponding author: E-mail: ruban_prabhu@yahoo.com; prabhuruban51@gmail.com

Densities, viscosities and ultrasonic velocities of binary liquid mixtures of methyl benzoate with chlorobenzene and benzaldehyde have been measured at $308.15 \mathrm{~K}$ and $318.15 \mathrm{~K}$. By these experimental data excess volume $\left(\mathrm{V}^{\mathrm{E}}\right)$, deviation in isentropic compressibility $\left(\Delta \mathrm{K}_{\mathrm{S}}\right)$, deviation in viscosity $(\Delta \eta)$ intermolecular free length $\left(\Delta \mathrm{L}_{\mathrm{f}}\right)$, intermolecular free volume $\left(\Delta \mathrm{V}_{\mathrm{f}}\right)$ and deviation in acoustic impedance $(\Delta \mathrm{Z})$ were calculated. These results have been correlated with the Redlich and Kister type polynomial equation to derive the coefficients and standard errors. Significance of the calculated excess quantities were analyzed for mixtures of methyl benzoate with chlorobenzene and benzaldehyde, through which intermolecular interactions have been investigated.

Keywords: Density, Viscosity, Ultrasonic velocity, Excess properties, Binary mixture, Molecular interaction.

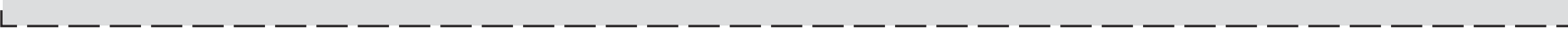

\section{INTRODUCTION}

Analysis of thermodynamic properties is most significant method that can expose the types of intermolecular interactions between two liquids. The experimental values of thermodynamic parameters can be explained to decide in terms of specific and non-specific interactions taking place between the molecules of the mixtures. The results of excellent interaction between the molecules can be considered as the appropriate solvent for the particular solute by this way. Methyl benzoate used as a flavours and fragrances in chemical industry. But methyl benzoate can also be used as the solvents of synthetic resins, cellulose esters and rubbers. Molecular interaction of methyl benzoate with ethanol at various temperatures have been investigated by Sheu and Tu [1]. Density, viscosity and speed of sound of methyl benzoate with cyclohexane, $n$-hexane, heptane and octane have been studied by Rathnam et al. [2]. Density and viscosity studies of $N, N$-dimethylformamide with methyl benzoate have been performed by Nikam and Kharat [3]. Thermophysical properties of methyl benzoate with $o$-xylene, $m$-xylene, $p$-xylene have been studies by Rathnam et al. [4]. Acoustic properties for the binary mixtures of methyl benzoate with 1-propanol and 1-butanol and 1-pentanol have been investigated by Sastry et al. [5]. Excess enthalpies and excess volumes for alkyl acetates and alkyl benzoates with aliphatic and aromatic hydrocarbon have been discussed by Grolier et al. [6]. Thermodynamic, dielectric, conformational studies of methyl benzoate with propane-1-ol have been reported by Mohan et al. [7]. Studies on densities and viscosities of binary mixtures of methyl benzoate in $n$-heptane is reported by Blanco et al. [8]. Study of molecular interaction of binary mixture of methyl benzoate by using viscometric and ultrasonic study has been reported by Rathnam et al. [9]. This work is to study the excess properties of binary mixture of methyl benzoate with chlorobenzene and benzaldehyde at different temperatures and molecular interactions have been discussed.

\section{EXPERIMENTAL}

Chlorobenzene (Merck Chemicals, Mumbai) with purity of $>99 \%$ (Merck Chemicals, Mumbai) with purity of $>99 \%$ was dried over anhydrous calcium chloride and distilled twice. Benzaldehyde (Merck Chemicals, Mumbai, purity > $99 \%$ ) was purified by double distillation and methyl benzoate (Merck Chemicals, Mumbai, purity > $99 \%$ ) single distilled.

The solvents purity is established by comparing experimental values of densities, viscosities and ultrasonic velocities with reported in the literature values. Present experimental values of densities, viscosities and ultrasonic velocities matched well with the reported values and are presented in Table-1.

A set of nine compositions was prepared for each mixture, and their physical properties were measured at the respective compositions in the mole fraction scale from 0.1 to 0.9 in steps of 0.1. Binary liquid mixtures of various compositions were prepared by mixing fixed amount of pure liquids in air tight stoppered bottles of $50 \mathrm{~mL}$ capacity. Densities of pure liquids and liquid mixtures were measured by relative density method 
TABLE-1

COMPARISON OF EXPERIMENTAL DENSITY $(\rho)$, VISCOSITY $(\eta)$, ULTRASONIC

VELOCITY (U) OF PURE LIQUIDS WITH LITERATURE VALUES AT 308.15 K and $318.15 \mathrm{~K}$

\begin{tabular}{lccc|cc|cc}
\hline \multirow{2}{*}{ Liquid } & \multirow{2}{*}{ Temp. $(\mathrm{K})$} & \multicolumn{2}{c|}{ Density $\left(\mathrm{g} \mathrm{cm}^{-3}\right)$} & \multicolumn{2}{c|}{ Viscosity $\left(\mathrm{mPa} \mathrm{s}^{-1}\right)$} & \multicolumn{2}{c}{ Ultrasonic velocity $\left(\mathrm{m} \mathrm{s}^{-1}\right)$} \\
\cline { 2 - 8 } & & Expt. & Lit. & Expt. & Lit. & Expt. & Lit. \\
\hline \multirow{2}{*}{ Methyl benzoate } & 308 & 1.0777 & $1.0743[1]$ & 1.5203 & $1.5310[1]$ & 1359.5 & $1364.0[2]$ \\
& 318 & 1.0648 & $1.0646[1]$ & 1.2960 & $1.2970[1]$ & 1335.5 \\
\hline \multirow{2}{*}{ Chlorobenzene } & 308 & 1.0941 & $1.0904[11]$ & 0.7040 & $0.6830[14]$ & 1228.0 & $1224.0[12]$ \\
& 318 & 1.0793 & $1.0790[11]$ & 0.6944 & & 1208.5 & $1194.0[10]$ \\
\hline \multirow{2}{*}{ Benzaldehyde } & 308 & 1.0381 & $1.0313[12]$ & 1.2483 & $1.2490[12]$ & 1417.5 & $1421.2[13]$ \\
& 318 & 1.0233 & $1.0229[13]$ & 1.0508 & & 1395.0 \\
\hline
\end{tabular}

[15-18] using $10 \mathrm{~mL}$ relative density bottle and weighed with an accuracy of $\pm 0.001 \mathrm{~kg} \mathrm{~m}^{-3}$. Viscosities were determined using an Oswald viscometer of $10 \mathrm{~mL}$ capacity with an accuracy of $\pm 0.001 \mathrm{mPa}[15-19]$. From the measured values of density $(\rho)$ and flow time $(t)$, viscosity $(\eta)$ was calculated using the following relation [14-17]:

$$
\eta=(\mathrm{A} \times \mathrm{t}-\mathrm{B} / \mathrm{t}) \times \rho
$$

where $\mathrm{A}$ and $\mathrm{B}$ are viscometer constants. The values of constants were obtained by measuring the flow time with distilled water and pure nitrobenzene as standard liquids. The flow time were measured with electronic stop clock. Ultrasonic velocities of pure and liquid mixtures were measured by a single crystal variable path interferometer (Pico Chennai, Model BL-02) [18] at a frequency of $2 \mathrm{MHz}$ with an accuracy of $\pm 0.02 \%$. All the measurements were made at 308.15 and $318.15 \mathrm{~K}$ with the help of a digital thermostat with a temperature accuracy of $\pm 0.01 \mathrm{~K}$.

The excess volume $\mathrm{V}^{\mathrm{E}}$ was calculated by the relation [13-17]:

$$
\begin{aligned}
V^{E}= & {\left[\left[X_{A} M_{A}+X_{B} M_{B}\right] / \rho_{A B}\right]-} \\
& {\left.\left[\left[X_{A} M_{A} / \rho_{A}\right]+\left[X_{B} M_{B}\right] / \rho_{B}\right]\right] }
\end{aligned}
$$

where $X_{A}, X_{B}$ are mole fraction of components $A$ and $B, M_{A}$, $M_{B}$ are the molecular mass of components $A \& B . \rho_{A}$ and $\rho_{B}$ are the density of component $A$ and $B$, respectively and $\rho_{A B}$ is the density of mixture.

Values of ultrasonic velocity $(\mathrm{u})$ and density of mixture $\left(\rho_{\mathrm{AB}}\right)$ were used to calculate isentropic compressibility $\left(\mathrm{K}_{\mathrm{S}}\right)$ by using following relation recommended by Benson and Kiyohara [20-24]:

$$
\mathrm{K}_{\mathrm{S}}=1 / \mathrm{U}^{2} \rho
$$

where, $\mathrm{U}$ is the ultrasonic velocity of pure and mixture, and $\rho$ is the density of pure and mixture.

The deviation in isentropic compressibility was obtained from the relation:

$$
\Delta \mathrm{K}_{\mathrm{S}}=\mathrm{KS}-\left(\Phi_{1} \mathrm{~K}_{\mathrm{S} 1}+\Phi_{2} \mathrm{~K}_{\mathrm{S} 2}\right)
$$

where $\Phi_{1}$ and $\Phi_{2}$ are the volume fraction of component 1 and $2, \mathrm{~K}_{\mathrm{S} 1}$ and $\mathrm{K}_{\mathrm{S} 2}$ are the isentropic compressibility of component 1 and 2 . $\mathrm{K}_{\mathrm{S}}$ is the experimental value of isentropic compressibility of the mixture.

Deviation in acoustic impedance $\Delta \mathrm{Z}$ and deviation in intermolecular free length $\left(\Delta \mathrm{L}_{\mathrm{f}}\right)$ has been calculated from the following relation $[24,25]$ :

$$
\begin{gathered}
\mathrm{L}_{\mathrm{f}}=\mathrm{k} / \mathrm{U} \rho^{1 / 2} \\
\mathrm{Z}=\mathrm{U} \rho
\end{gathered}
$$

where, $\mathrm{U}$ is the ultrasonic velocity of pure and mixture, and $\rho$ is the density of pure and mixture, $\mathrm{k}$ is the Jacobson's constant which is temperature dependent but independent of the nature of the liquids, whose value is $(91.368+0.3565 \mathrm{~T}) 9 \times 10^{-8}$ and is obtained from the literature [26].

$$
\mathrm{V}_{\mathrm{f}}=\left[\mathrm{M}_{\mathrm{eff}} \mathrm{U} / \mathrm{k} \eta\right]^{3 / 2}
$$

where $\mathrm{k}$ is a constant equal to $4.28 \times 10^{9}$ in MKS system [27], independent of temperature for all liquids, $\mathrm{M}_{\mathrm{eff}}$ is the effective molecular weight. $\mathrm{M}_{\text {eff }}=\Sigma \mathrm{x}_{\mathrm{i}} \mathrm{m}_{\mathrm{i}}$ where, $\mathrm{x}$ is the mole fraction and $\mathrm{m}$ is the molecular weight of ith component.

$$
\Delta \mathrm{Y}=\mathrm{Y}_{\text {mix }}-\mathrm{x}_{1} \mathrm{Y}_{1}+\mathrm{x}_{2} \mathrm{Y}_{2}
$$

where $\Delta \mathrm{Y}$ is $\Delta \eta$ or $\Delta \mathrm{V}_{\mathrm{f}}$ or $\Delta \mathrm{L}_{\mathrm{f}}$ or $\Delta \mathrm{Z}$ and $\mathrm{x}$ represent mole fraction of the component and subscript 1 and 2 for components 1 and 2.

\section{RESULTS AND DISCUSSION}

Experimental values of density $(\rho)$, viscosity $(\eta)$ and ultrasonic velocity $(\mathrm{u})$ were measured from which, calculated values of excess volume $\mathrm{V}^{\mathrm{E}}$, deviation in isentropic compressibility $\left(\Delta \mathrm{K}_{\mathrm{S}}\right)$ of all the five binary mixtures are presented in Tables 2 and 3. The excess properties of $\mathrm{V}^{\mathrm{E}}, \Delta \mathrm{K}_{\mathrm{S}}, \Delta \eta, \mathrm{L}_{\mathrm{f}}^{\mathrm{E}}$ and $\Delta \mathrm{Z}$ were fitted to Redlich-Kister [28] type polynomial equation:

$$
\Delta \mathrm{A}=\mathrm{x}_{1} \mathrm{x}_{2}\left[\mathrm{a}+\mathrm{b}\left(\mathrm{x}_{1}-\mathrm{x}_{2}\right)+\mathrm{c}\left(\mathrm{x}_{1}-\mathrm{x}_{2}\right)\right]
$$

By the method of least squares to derive the adjustable parameters $\mathrm{a}, \mathrm{b}$ and $\mathrm{c}$.

The standard deviations $(\sigma)$ presented in this work were computed using the following relation:

$$
\sigma=\sum\left(\frac{\left(\mathrm{X}_{\text {exp }}-\mathrm{X}_{\mathrm{cal}}\right)^{2}}{\mathrm{~N}-\mathrm{n}}\right)^{1 / 2}
$$

where $\mathrm{N}$ is the number of data points and $\mathrm{n}$ is the number of coefficients.

The excess volumes $\left(\mathrm{V}^{\mathrm{E}}\right)$, deviation in isentropic compressibility $\left(\Delta \mathrm{K}_{\mathrm{S}}\right)$, deviation in viscosity $(\Delta \eta)$, deviation in intermolecular free length $\left(\Delta \mathrm{L}_{\mathrm{f}}\right)$, deviation in intermolecular free volume $\left(\Delta V_{f}\right)$ and deviation in acoustic impedance $(\Delta \mathrm{Z})$ for all six liquid mixtures at two temperatures are presented in Figs. 1-6.

The excess volume provide good information about the intermolecular behaviour. The factors that are dependable for increase in volume are as follows: (i) loss of dipolar association, (ii) the geometry of molecular structure, which does not allow fitting of one component into other component, (iii) steric hindrance, which opposes the proximity of constituent molecules [29]. In the present work, benzaldehyde and chlorobenzene shows positive values of $\mathrm{V}^{\mathrm{E}}$ with methyl benzoate (Fig. 1). But benzaldehyde mixture seems to be low positive chlorobenzene mixture that revealed methyl benzoate + benzaldehyde mixture interact more than methyl benzoate + chlorobenzene mixture. 
TABLE-2

PHYSICAL AND THERMODYNAMIC PROPERTIES OF METHYL BENZOATE WITH CHLOROBENZENE AND BENZALDEHYDE AT 308.15 K

\begin{tabular}{|c|c|c|c|c|c|c|c|c|c|}
\hline $\mathrm{x}_{1}$ & $\begin{array}{c}\rho \\
\left(\mathrm{g} \mathrm{cm}^{-3}\right)\end{array}$ & $\begin{array}{c}\mathrm{V}^{\mathrm{E}} \\
\left(\mathrm{cm}^{3} \mathrm{~mol}^{-1}\right)\end{array}$ & $\begin{array}{c}\eta \\
(\mathrm{mPa} \mathrm{s})\end{array}$ & $\begin{array}{c}\mathrm{U} \\
\left(\mathrm{m} \mathrm{s}^{-1}\right)\end{array}$ & $\begin{array}{c}\Delta \mathrm{K}_{\mathrm{s}} \\
\left(\mathrm{Tpa}^{-1}\right)\end{array}$ & $\begin{array}{c}\Delta \eta \\
(\mathrm{mPa} \mathrm{s})\end{array}$ & $\begin{array}{c}\Delta \mathrm{L}_{\mathrm{f}} \\
\left(10^{-10} \mathrm{~m}\right)\end{array}$ & $\begin{array}{c}\Delta \mathrm{Z} \\
\left(10^{-6} \mathrm{Kg} \mathrm{m}^{2} \mathrm{~s}^{-1}\right)\end{array}$ & $\begin{array}{c}\Delta \mathrm{V}_{\mathrm{f}} \\
\left(10^{-15} \mathrm{~m}^{3} \mathrm{~mol}^{-1}\right)\end{array}$ \\
\hline \multicolumn{10}{|c|}{ Methyl benzoate + Chlorobenzene } \\
\hline 0.0000 & 1.0931 & 0.0000 & 0.7033 & 1228.00 & 0.0000 & 0.0000 & 0.0000 & 0.0000 & 0.0000 \\
\hline 0.0992 & 1.0908 & 0.0398 & 0.7644 & 1236.5 & 5.3732 & -0.0200 & 0.1044 & -5.6699 & $-3.80 \times 10^{-15}$ \\
\hline 0.2154 & 1.0884 & 0.0842 & 0.8432 & 1244.0 & 13.4221 & -0.0361 & 0.2840 & -14.8478 & $-7.10 \times 10^{-15}$ \\
\hline 0.2985 & 1.0867 & 0.1126 & 0.9024 & 1249.5 & 18.6279 & -0.0448 & 0.4071 & -21.1441 & $-8.40 \times 10^{-15}$ \\
\hline 0.4077 & 1.0847 & 0.1425 & 0.9829 & 1258.0 & 23.7905 & -0.0534 & 0.5361 & -27.8680 & $-8.90 \times 10^{-15}$ \\
\hline 0.5025 & 1.0831 & 0.1552 & 1.0574 & 1267.0 & 26.3690 & -0.0564 & 0.6070 & -31.7280 & $-8.70 \times 10^{-15}$ \\
\hline 0.6055 & 1.0817 & 0.1427 & 1.1456 & 1282.5 & 23.7038 & -0.0523 & 0.5486 & -29.3682 & $-7.80 \times 10^{-15}$ \\
\hline 0.6997 & 1.0807 & 0.1131 & 1.2299 & 1299.0 & 19.2294 & -0.0450 & 0.4451 & -24.4659 & $-6.40 \times 10^{-15}$ \\
\hline 0.7999 & 1.0797 & 0.0765 & 1.3231 & 1319.0 & 12.6309 & -0.0337 & 0.2895 & -16.5270 & $-4.50 \times 10^{-15}$ \\
\hline 0.9004 & 1.0787 & 0.0367 & 1.4192 & 1340.0 & 5.6119 & -0.0198 & 0.1247 & -7.5101 & $-2.30 \times 10^{-15}$ \\
\hline 1.00000 & 1.0777 & 0.0000 & 1.5203 & 1359.50 & 0.0000 & 0.0000 & 0.0000 & 0.0000 & 0.0000 \\
\hline \multicolumn{10}{|c|}{ Methyl benzoate + Benzaldehyde } \\
\hline 0.0000 & 1.0381 & 0.0000 & 1.2483 & 1417.50 & 0.0000 & 0.0000 & 0.0000 & 0.0000 & 0.0000 \\
\hline 0.0962 & 1.0425 & 0.0256 & 1.2710 & 1416.00 & -3.6193 & -0.0034 & -0.0966 & 5.2155 & $2.20 \times 10^{-16}$ \\
\hline 0.2019 & 1.0470 & 0.0539 & 1.2967 & 1417.00 & -9.1316 & -0.0065 & -0.2468 & 13.3875 & $5.10 \times 10^{-16}$ \\
\hline 0.3014 & 1.0511 & 0.0828 & 1.3219 & 1417.50 & -13.7878 & -0.0084 & -0.3731 & 20.3165 & $7.40 \times 10^{-16}$ \\
\hline 0.3972 & 1.0549 & 0.1062 & 1.3465 & 1414.50 & -15.7726 & -0.0098 & -0.4245 & 23.1389 & $8.60 \times 10^{-16}$ \\
\hline 0.4885 & 1.0585 & 0.1176 & 1.3706 & 1410.00 & -16.4494 & -0.0106 & -0.4407 & 24.0173 & $9.06 \times 10^{-16}$ \\
\hline 0.5921 & 1.0626 & 0.1047 & 1.3991 & 1402.00 & -15.1536 & -0.0102 & -0.4044 & 21.9897 & $8.37 \times 10^{-16}$ \\
\hline 0.6995 & 1.0668 & 0.0781 & 1.4298 & 1391.00 & -11.7358 & -0.0087 & -0.3112 & 16.8498 & $6.59 \times 10^{-16}$ \\
\hline 0.7990 & 1.0706 & 0.0493 & 1.4593 & 1379.00 & -7.0197 & -0.0063 & -0.1839 & 9.8988 & $4.15 \times 10^{-16}$ \\
\hline 0.9035 & 1.0744 & 0.0195 & 1.4912 & 1367.00 & -2.1598 & -0.0029 & -0.0548 & 2.9310 & $1.48 \times 10^{-16}$ \\
\hline 1.0000 & 1.0777 & 0.0000 & 1.5203 & 1359.50 & 0.0000 & 0.0000 & 0.0000 & 0.0000 & 0.0000 \\
\hline
\end{tabular}

TABLE-3

PHYSICAL AND THERMODYNAMIC PROPERTIES OF METHYL BENZOATE WITH CHLOROBENZENE AND BENZALDEHYDE AT 318.15 K

\begin{tabular}{|c|c|c|c|c|c|c|c|c|c|}
\hline $\mathrm{x}_{1}$ & $\begin{array}{c}\rho \\
\left(\mathrm{g} \mathrm{cm}^{-3}\right)\end{array}$ & $\begin{array}{c}\mathrm{V} \\
\left(\mathrm{cm}^{3} \mathrm{~mol}^{-1}\right) \\
\end{array}$ & $\begin{array}{c}\eta \\
(\mathrm{mPa} \mathrm{s}) \\
\end{array}$ & $\begin{array}{c}\mathrm{U} \\
\left(\mathrm{m} \mathrm{s}^{-1}\right)\end{array}$ & $\begin{array}{c}\Delta \mathrm{K}_{\mathrm{s}} \\
\left(\mathrm{Tpa}^{-1}\right)\end{array}$ & $\begin{array}{c}\Delta \eta \\
(\mathrm{mPa} \mathrm{s})\end{array}$ & $\begin{array}{c}\Delta \mathrm{L}_{\mathrm{f}} \\
\left(10^{-10} \mathrm{~m}\right)\end{array}$ & $\begin{array}{c}\Delta \mathrm{Z} \\
\left(10^{-6} \mathrm{Kg} \mathrm{m}^{2} \mathrm{~s}^{-1}\right)\end{array}$ & $\begin{array}{c}\Delta \mathrm{V}_{\mathrm{f}} \\
\left(10^{-15} \mathrm{~m}^{3} \mathrm{~mol}^{-1}\right)\end{array}$ \\
\hline \multicolumn{10}{|c|}{ Methyl benzoate + Chlorobenzene } \\
\hline 0.0000 & 1.0792 & 0.0000 & 0.6944 & 1208.50 & 0.0000 & 0.0000 & 0.0000 & 0.0000 & 0.0000 \\
\hline 0.0992 & 1.0770 & 0.0530 & 0.7307 & 1213.0 & 9.4544 & -0.0234 & 0.2070 & -9.5627 & $-6.7 \times 10^{-16}$ \\
\hline 0.2154 & 1.0746 & 0.1063 & 0.7789 & 1219.0 & 19.0032 & -0.0451 & 0.4254 & -19.7465 & $-1.6 \times 10^{-15}$ \\
\hline 0.2985 & 1.0729 & 0.1418 & 0.8182 & 1223.5 & 25.1666 & -0.0557 & 0.5740 & -26.6954 & $-2.4 \times 10^{-15}$ \\
\hline 0.4077 & 1.0710 & 0.1703 & 0.8732 & 1231.0 & 31.0775 & -0.0665 & 0.7227 & -33.8392 & $-2.9 \times 10^{-15}$ \\
\hline 0.5025 & 1.0696 & 0.1828 & 0.9258 & 1239.5 & 33.7953 & -0.0708 & 0.7983 & -37.7113 & $-3.2 \times 10^{-15}$ \\
\hline 0.6055 & 1.0683 & 0.1709 & 0.9925 & 1254.5 & 30.8107 & -0.0662 & 0.7339 & -35.4248 & $-3.2 \times 10^{-15}$ \\
\hline 0.6997 & 1.0673 & 0.1451 & 1.0571 & 1271.5 & 25.0255 & -0.0582 & 0.5988 & -29.6457 & $-2.8 \times 10^{-15}$ \\
\hline 0.7999 & 1.0664 & 0.1029 & 1.1305 & 1290.0 & 18.6926 & -0.0450 & 0.4519 & -22.8730 & $-2.1 \times 10^{-15}$ \\
\hline 0.9004 & 1.0656 & 0.0521 & 1.2095 & 1311.5 & 10.1378 & -0.0265 & 0.2474 & -12.8432 & $-1.1 \times 10^{-15}$ \\
\hline 1.0000 & 1.0648 & 0.0000 & 1.2960 & 1335.50 & 0.0000 & 0.0000 & 0.0000 & 0.0000 & 0.0000 \\
\hline \multicolumn{10}{|c|}{ Methyl benzoate + Benzaldehyde } \\
\hline 0.0000 & 1.0233 & 0.0000 & 1.0508 & 1395.00 & 0.0000 & 0.0000 & 0.0000 & 0.0000 & 0.0000 \\
\hline 0.0962 & 1.0278 & 0.0346 & 1.0698 & 1392.00 & -2.8614 & -0.0046 & -0.0741 & 3.6915 & $3.88 \times 10^{-16}$ \\
\hline 0.2019 & 1.0325 & 0.0749 & 1.0920 & 1389.50 & -6.3036 & -0.0083 & -0.1641 & 8.1954 & $7.60 \times 10^{-16}$ \\
\hline 0.3014 & 1.0367 & 0.1084 & 1.1140 & 1388.50 & -10.3071 & -0.0107 & -0.2715 & 13.5986 & $1.10 \times 10^{-15}$ \\
\hline 0.3972 & 1.0407 & 0.1335 & 1.1357 & 1386.00 & -12.8815 & -0.0125 & -0.3396 & 17.0412 & $1.32 \times 10^{-15}$ \\
\hline 0.4885 & 1.0445 & 0.1434 & 1.1570 & 1382.00 & -14.0557 & -0.0136 & -0.3703 & 18.5889 & $1.43 \times 10^{-15}$ \\
\hline 0.5921 & 1.0488 & 0.1306 & 1.1830 & 1373.00 & -12.0082 & -0.0129 & -0.3132 & 15.6795 & $1.25 \times 10^{-15}$ \\
\hline 0.6995 & 1.0532 & 0.1038 & 1.2112 & 1363.00 & -9.1479 & -0.0110 & -0.2363 & 11.7867 & $9.90 \times 10^{-16}$ \\
\hline 0.7990 & 1.0572 & 0.0700 & 1.2384 & 1352.50 & -5.3134 & -0.0083 & -0.1345 & 6.6779 & $6.44 \times 10^{-16}$ \\
\hline 0.9035 & 1.0612 & 0.0316 & 1.2679 & 1342.50 & -1.7769 & -0.0044 & -0.0430 & 2.1259 & $2.75 \times 10^{-16}$ \\
\hline 1.0000 & 1.0648 & 0.0000 & 1.2960 & 1335.50 & 0.0000 & 0.0000 & 0.0000 & 0.0000 & 0.0000 \\
\hline
\end{tabular}

Compressibility of a liquid is the vital physical quantities in liquid mechanics. It depends on the structure of the liquid [30]. Intermolecular free length $\left(\mathrm{L}_{\mathrm{f}}\right)$ is the distance between the surfaces of two molecules, which establish the properties of fluids consists of attractive and repulsive forces. According to Fort and Moore [31] a negative value of deviation in compressibility $\left(\Delta \mathrm{K}_{\mathrm{S}}\right)$ and deviation in intermolecular free length $\left(\Delta \mathrm{L}_{\mathrm{f}}\right)$ are the suggestion of strong heteromolecular interaction in the liquid mixtures, while a positive sign specify weak interaction and is accredited to dispersion forces.

The $\Delta \mathrm{K}_{\mathrm{S}}$ and $\Delta \mathrm{L}_{\mathrm{f}}$ values of chlorobenzene is positive and benzaldehyde is negative with methyl benzoate (Fig. 2), it ascribed that benzaldehyde is attracted towards methyl benzoate molecules and chlorobenzene dispersed methyl benzoate molecules (Table-4). The physical contribution consists of dispersion forces or weak interaction that leads to positive values of $\Delta \mathrm{K}_{\mathrm{S}}$ and $\Delta \mathrm{L}_{\mathrm{f}}[32,33]$. 


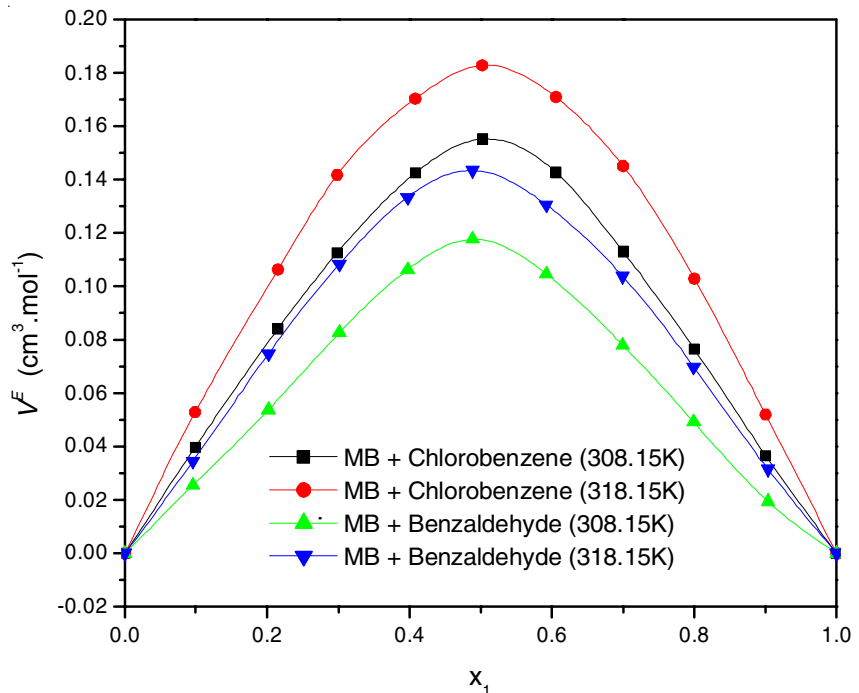

Fig. 1. Excess volume $\left(\mathrm{V}^{\mathrm{E}}\right)$ for methyl benzoate $(\mathrm{MB})$ with chlorobenzene and benzaldehyde at $308.15 \mathrm{~K}$ and $318.15 \mathrm{~K}$

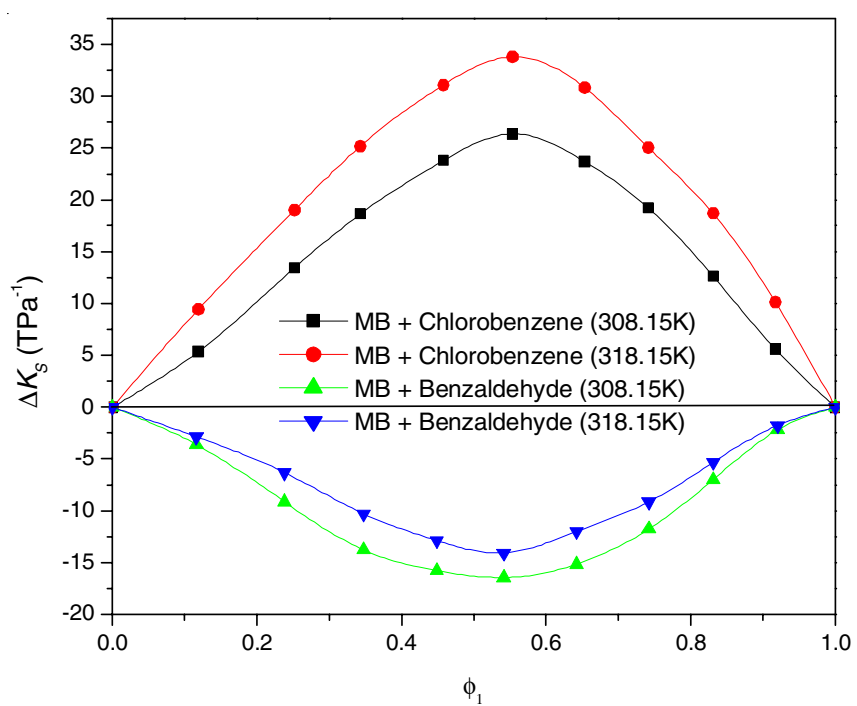

Fig. 2. $\Delta \mathrm{K}_{\mathrm{S}}$ for methyl benzoate $(\mathrm{MB})$ with chlorobenzene and benzaldehyde at $308.15 \mathrm{~K}$ and $318.15 \mathrm{~K}$

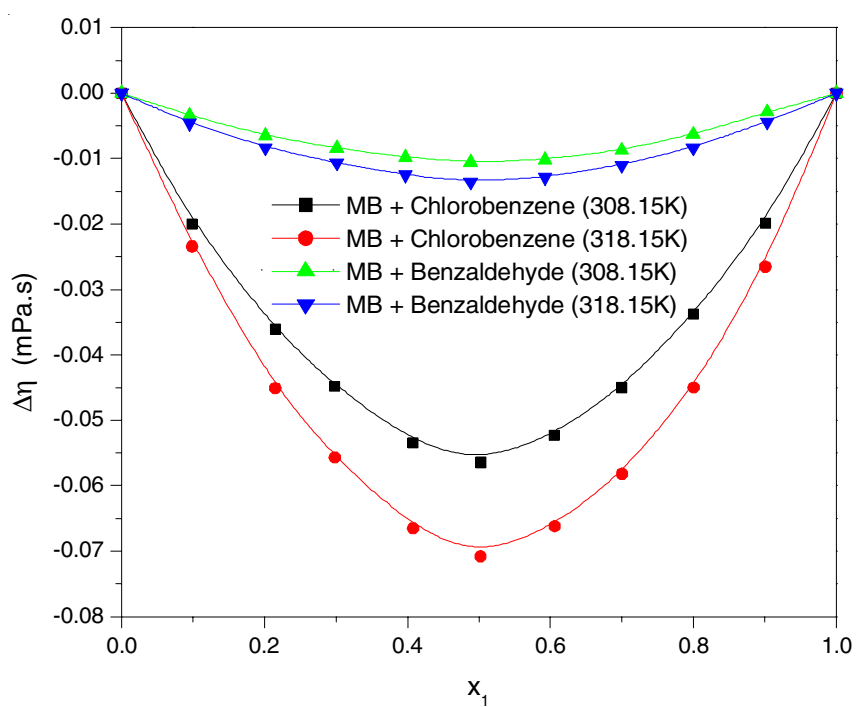

Fig. 3. $\Delta \eta$ for methyl benzoate (MB) with chlorobenzene and benzaldehyde at 308.15 and $318.15 \mathrm{~K}$

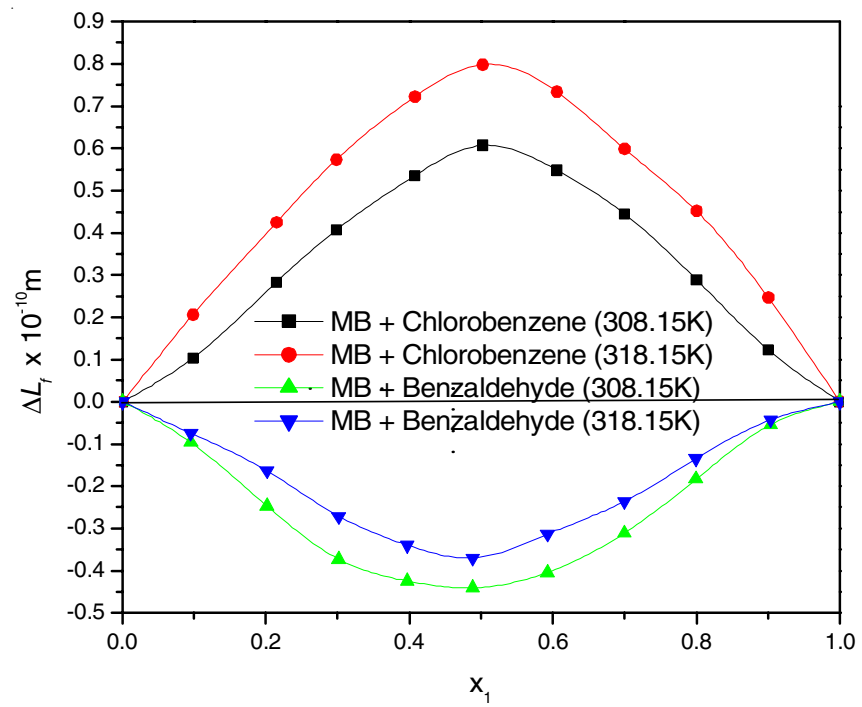

Fig. 4. $\Delta \mathrm{L}_{\mathrm{f}}$ for methyl benzoate (MB) with chlorobenzene and benzaldehyde at 308.15 and $318.15 \mathrm{~K}$

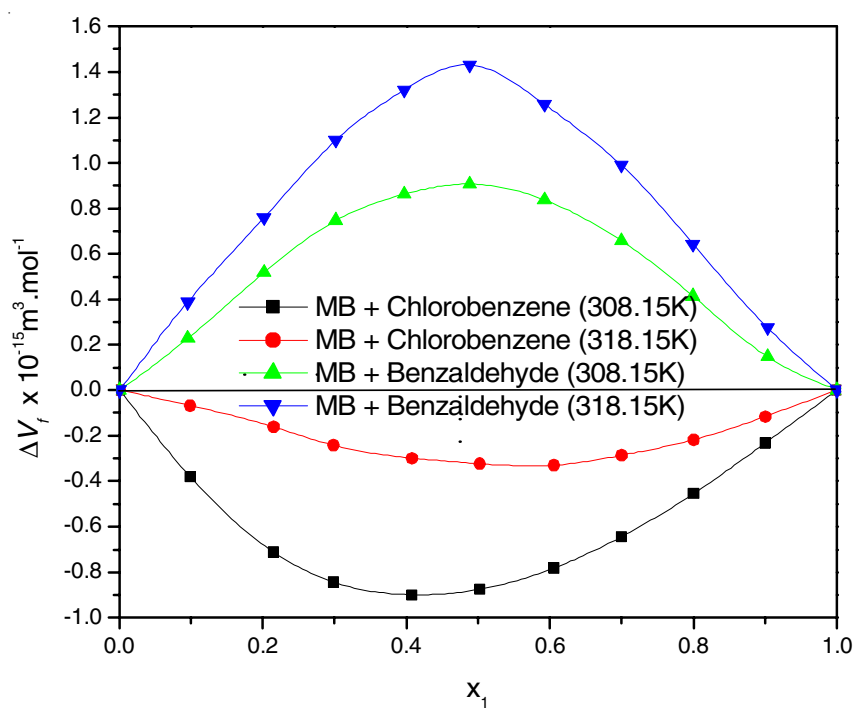

Fig. 5. $\Delta \mathrm{V}_{\mathrm{f}}$ for methyl benzoate (MB) chlorobenzene and benzaldehyde at 308.15 and $318.15 \mathrm{~K}$

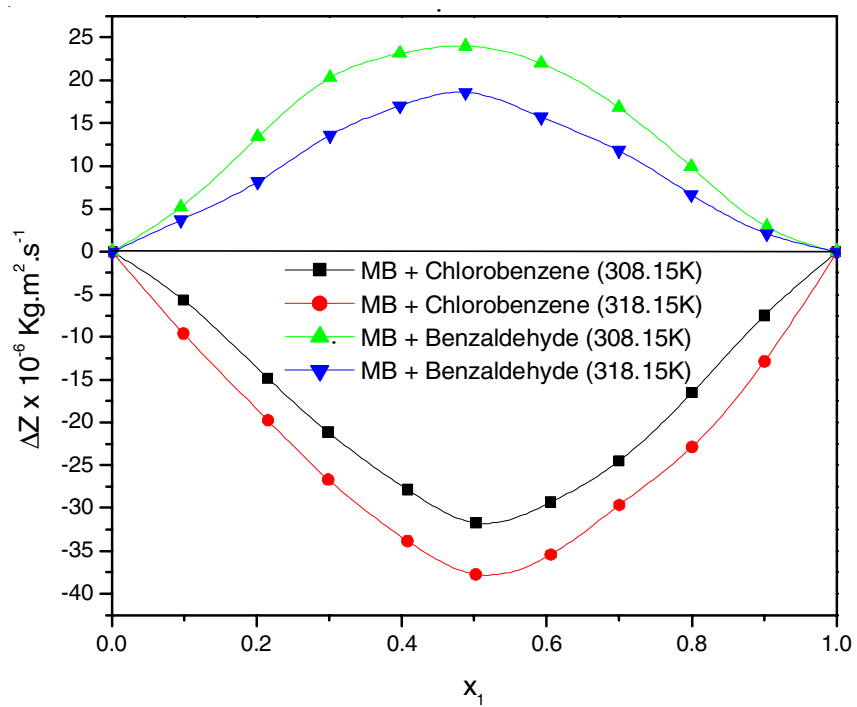

Fig. 6. $\Delta \mathrm{Z}$ for methyl benzoate $(\mathrm{MB})$ with chlorobenzene and benzaldehyde at 308.15 and $318.15 \mathrm{~K}$ 


\begin{tabular}{|c|c|c|c|c|c|c|c|c|}
\hline \multirow{3}{*}{ Temp. (K) } & \multicolumn{7}{|c|}{$\begin{array}{l}\text { TABLE-4 } \\
\text { VALUES OF THE CO-EFFICIENT OF THE REDLICH-KISTER TYPE POLYNOMIAL EQUATION } \\
\text { (eqn. 9) AND STANDARD DEVIATION (eqn. 10) AT THE DIFFERENT TEMPERATURE }\end{array}$} & \\
\hline & \multicolumn{4}{|c|}{ Methyl benzoate + Chlorobenzene } & \multicolumn{4}{|c|}{ Methyl benzoate + Benzaldehyde } \\
\hline & $\mathrm{a}$ & $\mathrm{b}$ & $\mathrm{c}$ & $\sigma$ & $\mathrm{a}$ & $\mathrm{b}$ & $\mathrm{c}$ & $\sigma$ \\
\hline & \multicolumn{4}{|c|}{$\mathrm{V}^{\mathrm{E}}\left(\mathrm{cm}^{3} \mathrm{~mol}^{-1}\right)$} & \multicolumn{4}{|c|}{$\mathrm{V}^{\mathrm{E}}\left(\mathrm{cm}^{3} \mathrm{~mol}^{-1}\right)$} \\
\hline 308 & -0.0880 & 0.3790 & 0.1768 & 0.0449 & 0.8275 & -0.3475 & 0.2571 & 0.0367 \\
\hline \multirow[t]{2}{*}{318} & -0.0755 & 0.4457 & 0.0275 & 0.0051 & 0.3566 & -0.1396 & 0.1242 & 0.0092 \\
\hline & \multicolumn{4}{|c|}{$\Delta \eta(\mathrm{mPa} \mathrm{s})$} & \multicolumn{4}{|c|}{$\Delta \eta(\mathrm{mPa} \mathrm{s})$} \\
\hline 308 & 1.6342 & -6.1865 & 5.3876 & 0.2141 & -0.0402 & 0.0005 & 0.0068 & 0.0001 \\
\hline \multirow[t]{2}{*}{318} & 2.2362 & -5.3336 & 6.0809 & 0.2738 & -0.1107 & -0.0039 & 0.0107 & 0.0042 \\
\hline & \multicolumn{4}{|c|}{$\Delta \mathrm{K}_{\mathrm{s}}\left(\mathrm{Tpa}^{-1}\right)$} & \multicolumn{4}{|c|}{$\Delta \mathrm{K}_{\mathrm{s}}\left(\mathrm{Tpa}^{-1}\right)$} \\
\hline 308 & 100.81 & 27.7362 & -62.6938 & 0.0499 & -62.0592 & -27.1197 & 33.0251 & 0.1456 \\
\hline \multirow[t]{2}{*}{318} & 128.817 & 32.2414 & -38.9171 & 0.0298 & -53.9367 & -7.9224 & 46.3779 & 0.1023 \\
\hline & \multicolumn{4}{|c|}{$\Delta \mathrm{L}_{\mathrm{f}} \times 10^{-10} \mathrm{~m}$} & \multicolumn{4}{|c|}{$\Delta \mathrm{L}_{\mathrm{f}} \times 10^{-10} \mathrm{~m}$} \\
\hline 308 & $-5.81 \times 10^{-10}$ & $-2.52 \times 10^{-10}$ & $-3.36 \times 10^{-10}$ & $6.3701 \times 10^{-11}$ & $-2.04 \times 10^{-10}$ & $-7.33 \times 10^{-12}$ & $9.92 \times 10^{-11}$ & $2.3121 \times 10^{-12}$ \\
\hline \multirow[t]{2}{*}{318} & $-4.81 \times 10^{-10}$ & $-4.12 \times 10^{-10}$ & $-5.58 \times 10^{-10}$ & $4.5174 \times 10^{-11}$ & $2.68 \times 10^{-12}$ & $8.77 \times 10^{-12}$ & $-2.94 \times 10^{-11}$ & $1.1516 \times 10^{-13}$ \\
\hline & \multicolumn{4}{|c|}{$\Delta \mathrm{Z} \times 10^{-6} \mathrm{Kg} \mathrm{m}^{2} \mathrm{~s}^{-1}$} & \multicolumn{4}{|c|}{$\Delta \mathrm{Z} \times 10^{-6} \mathrm{Kg} \mathrm{m}^{2} \mathrm{~s}^{-1}$} \\
\hline 308 & -123.297 & -16.5277 & 81.5453 & 0.0078 & 97.1631 & -18.0452 & -71.0522 & 0.0114 \\
\hline \multirow[t]{2}{*}{318} & -145.693 & -21.2663 & 44.1346 & 0.0222 & 71.2854 & -10.2706 & -65.1788 & 0.0117 \\
\hline & \multicolumn{4}{|c|}{$\Delta \mathrm{V}_{\mathrm{f}} \times 10^{-15} \mathrm{~m}^{3} \mathrm{~mol}^{-1}$} & \multicolumn{4}{|c|}{$\Delta \mathrm{V}_{\mathrm{f}} \times 10^{-15} \mathrm{~m}^{3} \mathrm{~mol}^{-1}$} \\
\hline 308 & $1.43 \times 10^{-6}$ & $2.78 \times 10^{-7}$ & $4.27 \times 10^{-6}$ & $1.7441 \times 10^{-7}$ & $3.85 \times 10^{-15}$ & $7.96 \times 10^{-18}$ & $-1.52 \times 10^{-15}$ & $2.2208 \times 10^{-17}$ \\
\hline 318 & $1.39 \times 10^{-6}$ & $8.80 \times 10^{-8}$ & $3.96 \times 10^{-6}$ & $1.6115 \times 10^{-7}$ & $5.27 \times 10^{-14}$ & $8.60 \times 10^{-15}$ & $-3.09 \times 10^{-13}$ & $4.6195 \times 10^{-16}$ \\
\hline
\end{tabular}

Viscosity deviation is linked to the struggle of a mixture to flow, positive deviations of viscosity values for the mixtures are the effect of a higher resistance to flow than the pure compounds. Rowlinson and Swinton [34] stated that the positive deviation of the viscosities on mole fraction is the incidence of maxima where the component molecules interact more strongly. Negative deviations occured where London forces or dispersion forces are responsible for the interactions [35]. In the present work, both chlorobenzene and benzaldehyde got negative sign over the entire range, but benzaldehyde gets lower negative sign than chlorobenzene, this suggests that benzaldehyde attract more than chlorobenzene with methyl benzoate.

$\Delta \mathrm{Z}$ described how much resistance an ultrasound beam encounters as it passes through a liquid. Positive and negative deviations in these functions of the mixtures specify the extent of association or dissociation between the mixing components [36,37]. According to Kondaiah and Rao [38], the nature of the positive values of $\Delta \mathrm{Z}$ is attributed to specific interaction between the unlike molecules $\Delta \mathrm{Z}$ and $\Delta \mathrm{V}_{\mathrm{f}}$ values are positive over the entire range for benzaldehyde (Figs. 5 and 6) and negative over the whole array for chlorobenzene mixture.

From the above data, we can interpreted that benzaldehyde interact more with methyl benzoate than chlorobenzene, because benzaldehyde has more dipole moment (2.89 D) and dielectric constant (17.80) than chlorobenzene which has $1.54 \mathrm{D}$ and 5.62 , respectively (Table-4). Benzaldehyde contains carbonyl group, since carbonyl carbon gets partially positive charge due to inductive effect, the positive carbon may be approached by oxygen atom of the methylbenzoate. Although chlorobenzene has more electronegative chlorine atom, its polarity suppressed by the benzene ring, hence chlorobenzene is less polar molecule than benzaldehyde. Methyl benzoate interacts with benzaldehyde through dipole-dipole interaction. Both the two mixture molecules decreasing interaction with increasing temperature because of the thermal vibration they move away from each other.

\section{Conclusion}

This work has determined $\mathrm{V}^{\mathrm{E}}, \Delta \mathrm{K}_{\mathrm{S}}, \Delta \mathrm{L}_{\mathrm{f}}, \Delta \eta, \Delta \mathrm{V}_{\mathrm{f}}$ and $\Delta \mathrm{Z}$ for mixtures of methyl benzoate with chlorobenzene and benzaldehyde. The importances of $\mathrm{V}^{\mathrm{E}}$ and $\Delta \mathrm{K}_{\mathrm{S}}, \Delta \mathrm{L}_{\mathrm{f}}, \Delta \eta, \Delta \mathrm{V}_{\mathrm{f}}$ and $\Delta \mathrm{Z}$ have been interpreted in terms of different molecular interaction between those molecules. The magnitudes of excess properties have shown that methyl benzoate + benzaldehyde mixtures get strong specific interaction which is explained by dipole-dipole interaction between them. Interaction between methyl benzoate + chlorobenzene is described as dispersion force. Interaction decreases with increasing temperature because of thermal action.

\section{REFERENCES}

1. Y.-W. Sheu and C.-H. Tu, J. Chem. Eng. Data, 51, 545 (2006); https://doi.org/10.1021/je050402s.

2. M.V. Rathnam, S. Mankumare and M.S.S. Kumar, J. Chem. Eng. Data, 55, 1354 (2010);

https://doi.org/10.1021/je9006597.

3. P.S. Nikam and S.J. Kharat, J. Chem. Eng. Data, 50, 455 (2005); https://doi.org/10.1021/je040012q.

4. M.V. Rathnam, S. Mohite and M.S. Kumar, J. Chem. Eng. Data, 54, 305 (2009);

https://doi.org/10.1021/je800325d.

5. S.S. Sastry, B. Shaik, T. Vishwam and S.T. Ha, Phys. Chem. Liq.: An Int. J., 52, 272 (2014);

https://doi.org/10.1080/00319104.2013.820302.

6. J.-P.E. Grolier, D. Ballet and A. Viallard, J. Chem. Thermodyn., 6, 895 (1974);

https://doi.org/10.1016/0021-9614(74)90234-1.

7. T.M. Mohan, S.S. Sastry and V.R.K. Murthy, J. Solution Chem., 40, 131 (2011); https://doi.org/10.1007/s10953-010-9634-6.

8. A.M. Blanco, J. Ortega, B. Garcia and J.M. Leal, Thermochim. Acta, 222, 127 (1993);

https://doi.org/10.1016/0040-6031(93)80546-M.

9. M.V. Rathnam, R.T. Sayed, K.R. Bhanushali and M.S.S. Kumar, J. Mol. Liq., 166, 9 (2012);

https://doi.org/10.1016/j.molliq.2011.10.020.

10. K. Narendra, B. Sudhamsa, M. Babu and T.S. Krishna, J. Appl. Sol. Chem. Modeling, 4, 119 (2015);

https://doi.org/10.6000/1929-5030.2015.04.02.4 
11. N.V. Sastry, A. George, N.J. Jain and P. Bahadur, J. Chem. Eng. Data, 44, 456 (1999); https://doi.org/10.1021/je980174k.

12. T.G. Lavanya, K. Saravanakumar, R. Baskaran and T.T. Kubendran, Int. J. Thermophys., 34, 1280 (2013); https://doi.org/10.1007/s10765-013-1492-1.

13. N.I. Malek, S.P. Ijardar and S.B. Oswal, Thermochim. Acta, 539, 71 (2012); https://doi.org/10.1016/j.tca.2012.04.002.

14. J.N. Nayak, M.I. Aralaguppi and T.M. Aminabhavi, J. Chem. Eng. Data, 48, 628 (2003); https://doi.org/10.1021/je0201828.

15. S.S. Sastry, S. Babu, T. Vishwam and H.S. Tiong, J. Therm. Anal. Calorim., 116, 923 (2014); https://doi.org/10.1007/s10973-013-3570-9.

16. P. Vasantharani, L. Balu, R.E. Pavai and S. Shailajha, Global J. Mol. Sci., 4, 42 (2009).

17. A.R. Venis and X.R. Rajkumar, Asian J. Chem., 26, 4711 (2014); https://doi.org/10.14233/ajchem.2014.16182.

18. S. Felixa, U. Sivakami and R. Venis, World J. Pharm. Pharm. Sci., 5, 1602 (2016).

19. S. Kumar and P. Jeevanandham, J. Mol. Liq., 174, 34 (2012); https://doi.org/10.1016/j.molliq.2012.07.025.

20. O. Kiyohara and G.C. Benson, J. Chem. Thermodyn., 11, 861 (1979); https://doi.org/10.1016/0021-9614(79)90067-3.

21. G.C. Benson and O. Kiyohara, J. Chem. Thermodyn., 11, 1061 (1979); https://doi.org/10.1016/0021-9614(79)90136-8.

22. I. Alonso, I. Mozo, I.G. de la Fuente, J.A. González and J.C. Cobos, J. Chem. Eng. Data, 55, 5400 (2010); https://doi.org/10.1021/je100472t

23. M. Yasmin and M. Gupta, J. Solution Chem., 40, 1458 (2011); https://doi.org/10.1007/s10953-011-9731-1.

24. K.R. Reddy, D.B.K. Kumar, G.S. Rao, P. Anila and C. Rambabu, Thermochim. Acta, 590, 116 (2014); https://doi.org/10.1016/j.tca.2014.06.026.
25. S. Azhagiri, S. Jayakumar, R. Padmanaban, S. Gunasekaran and S. Srinivasan, J. Solution Chem., 38, 441 (2009); https://doi.org/10.1007/s10953-009-9383-6.

26. B. Jacobson, E. Halonen and C. Faurholt, Acta Chem. Scand., 6, 1485 (1952); https://doi.org/10.3891/acta.chem.scand.06-1485.

27. R. Thiyagarajan and L. Palaniappan, Phys. Chem. Liq., 46, 366 (2008); https://doi.org/10.1080/00319100701312807.

28. O. Redlich and A.T. Kister, Ind. Eng. Chem., 40, 345 (1948); https://doi.org/10.1021/ie50458a036.

29. K. Saravanakumar and T.R. Kubendran, Res. J. Chem. Sci., 2, 50 (2012).

30. S. Prakash and J.D. Pandey, J. Sci. Ind.. Res., 21B, 593 (1962).

31. R.J. Fort and W.R. Moore, Trans. Faraday Soc., 61, 2102 (1965); https://doi.org/10.1039/tf9656102102.

32. Sk. Md Nayeem, M. Kondaiah, K. Sreekanth and D. Krishna Rao, J. Thermodynam., Article ID 487403 (2014); https://doi.org/10.1155/2014/487403.

33. F. Nabi, M.A. Malik, C.G. Jesudason and S.A. Al-Thabaiti, Korean J. Chem. Eng., 31, 1505 (2014); https://doi.org/10.1007/s11814-014-0173-5.

34. J.S. Rowlinson and F.L. Swinton, Liquids and Liquid Mixtures, Butterworths, London, edn 3 (1982).

35. K. Liler, ed.: D. Hadzi, Hydrogen Bonding, Pergamon Press, London (1959).

36. A. Pal and R.K. Bhardwaj, Z. Phys. Chem., 216, 1033 (2002); https://doi.org/10.1524/zpch.2002.216.9.1033.

37. B. Sinha, Phys. Chem. Liq., 48, 183 (2010); https://doi.org/10.1080/00319100802706691.

38. M. Kondaiah and D. Krishna Rao, J. Mol. Liq., 195, 110 (2014); https://doi.org/10.1016/j.molliq.2014.02.010. 